\title{
A morfologia dos vasos Jê na produção de cauim de milho em Vereda III: uma proposição
}

\author{
Gilberto G. Gardiman * \\ Igor M.M. Rodrigues ** \\ Leandro M. Cascon *** \\ Andrei Isnardis ****
}

\begin{abstract}
GARDIMAN, G.G.; RODRIGUES, I.M.M.; CASCON, L.M.; ISNARDIS, A. A morfologia dos vasos Jê na produção de cauim de milho em Vereda III: uma proposição. $R$. Museu Arq. Etn., 27: 111-120, 2016
\end{abstract}

Resumo: A análise arqueobotânica focada em grânulos de amido extraídos de vasos cerâmicos e um artefato lítico exumados em Vereda III, MG revelou a presença generalizada do milho (Zea mays sp). Um estudo prévio realizado com os artefatos havia detectado marcas de uso típicas da fermentação em alguns vasos, assim, levantou-se a possibilidade de que mais vasos teriam sido utilizados na produção de cauim de milho. Tratou-se de compreender a produção dessa bebida/alimento nas suas múltiplas possibilidades através de relatos históricos, etnografias, informações tecnológicas e testes com fermentação. Os efeitos tafonômicos das distintas etapas do processo sobre os grânulos de amido de milho foram pesquisados em literatura e através de testes. Faz-se aqui uma proposição quanto à morfologia dos vasos Jê utilizados na elaboração do cauim de milho, pensada a partir do cruzamento de 2 tipos de evidências: o estudo dos microvestígios contidos nos artefatos arqueológicos e as marcas de uso nos vasos.

Palavras-chave: Arqueobotânica; Fermentação; Cauim de milho; Jê; Vasos cerâmicos.

\section{Introdução}

$\mathrm{O}$ vasos cerâmicos destinados à produção do cauim produzidos por grupos falantes Tupi e Guarani foram descritos em etnografias, pesquisas linguísticas e arqueologi-

$\left({ }^{*}\right)$ Graduação em Antropologia habilitação Arqueologia, UFMG; Engenheiro de alimentos, Mestrado em Planificação em Alimentação e Nutrição. 〈gttman@uol.com.br>

$\left.{ }^{* *}\right)$ Mestre em Antropologia com concentração em Arqueologia pelo PPGAN-UFMG. Centro Especializado em Arqueologia Pré-Histórica do MHNJB-UFMG.

<igor_mmrodrigues@hotmail.com>

${ }^{(* * *)}$ Graduação em História, UFC; Mestrado em Arqueolo- camente, cuja revisão (Noelli e Brochado 1998) permitiu a observação de que em cada etapa do processo de fermentação são usados vasos com nomes e morfologias específicas e, consequentemente, marcas de uso ao fogo similares. Com os Jê, isso não parece ser diferente. Assim, apresen-

gia pelo Museu Nacional/UFRJ; Doutorando em Arqueologia pelo Museu de Arqueologia e Etnologia /USP. Bolsista FAPESP.<lmcascon@gmail.com>

$(* * *)$ Cientista social com ênfase em Arqueologia. Mestrado e doutorado em Arqueologia. Professor adjunto do Departamento de Sociologia e Antropologia da UFMG; Centro Especializado em Arqueologia Pré-Histórica do MHNJB-U. FMG.<isnardis@gmail.com> 
tamos aqui uma proposição, ou seja, afirmação sujeita à confirmação, a respeito da morfologia de vasos cerâmicos destinados às etapas principais da elaboração do cauim por um grupo de tal filiação linguística.

Tal proposição é um dos produtos da pesquisa arqueobotânica (Gardiman 2014) realizada com vasos exumados em sua maioria de um contexto único encontrado no sítio Vereda III pela equipe de Walter Neves em 2003 (Neves et al. 2004). Posteriormente foram analisados, remontados e tiveram suas marcas de uso descritas por Rodrigues (2011), que buscou entender as especificidades do assentamento, entendimento esse apresentado em artigo neste número. Vereda III está localizado numa clareira cercada de abrigos, escondida sobre um afloramento rochoso na área de carste, a $80 \mathrm{~km}$ de Belo Horizonte. Os utensílios cerâmicos são atribuídos à tradição AratuSapucaí, portanto provenientes de grupo com filiação linguística Macro-Jê. Possuem capacidades volumétricas ou muito grandes ou pequenas, somando um total acima dos 2000 litros. Vasos com morfologia piriforme apresentam desplacamentos na superfície interna, o que é associado a uso em processo fermentativo (Rodrigues 2011).

A pesquisa arqueobotânica anteriormente mencionada tinha como objetivo inicial identificar os vegetais e os processos a que foram submetidos nos vasos. Porém, as observações da presença massiva de milho em todos artefatos, 12 cerâmicos e 1 lítico, aliadas às grandes capacidades volumétricas dos vasos e aos desplacamentos relacionados à fermentação em alguns deles, reforçaram a possibilidade de que o conjunto ou parte dele estaria ligado à atividade de produção de alimentos/bebidas fermentados de milho.

Tratou-se de levantar em relatos históricos e etnografias as etapas sequenciais mínimas e as opcionais para a obtenção do cauim alcoólico, produzido por grupos de diferentes filiações linguísticas e a definição das etapas mínimas foi analisada também sob critérios estabelecidos pela microbiologia e bioquímica dos alimentos. Direcionou-se a pesquisa laboratorial para o entendimento dos processos de produção de fermentados, em especial sob o aspecto dos microvestígios botânicos (grânulos de amido) e das modificações sofridas por esses durante as etapas do processo.
Diversos testes foram realizados para observar os efeitos dos processos de transformação dos alimentos sobre os grânulos de amido do milho, como a mastigação/insalivação, torra, torra/mastigação e moagem de milho.

A concatenação dos resultados arqueobotânicos com os dados acima permitiu uma tipificação dos vasos para a elaboração de cada etapa do processo, levando-se em conta a lógica das transformações na fermentação. Outras características, como presença de pintura, tipo de pasta cerâmica utilizada e presença de camada interna adicional de argila não foram aqui estudadas.

Apresentamos a seguir o desenvolvimento do trabalho, seus resultados e conclusões.

\section{Materiais}

Foram identificados no sítio 24 vasos (numerados de 1 a 24 por Rodrigues), muitos deles com mais de 50 litros de capacidade, e que foram divididos em 3 grupos, conforme a pasta cerâmica com que foram fabricados.

Num dos grupos estão potes pequenos e de paredes finas, hemisféricos e globulares, todos com alisamento na face interna e/ou externa e queima redutora. Apresentaram marcas de fuligem lustrosa nas faces externas, indicando exposição ao fogo, ou seja, uso como pequenas panelas. Exceto um deles, todos apresentaram engobo vermelho (Rodrigues 2011). Deste grupo, foram analisados os potes 9 , hemisférico, e os potes 17 e 24, globulares.

Em outro grupo estão dois grandes potes piriformes (7 e 13), com capacidades de 200 e $417 \mathrm{~L}$ respectivamente, com camada adicional de argila com cerca de $1 \mathrm{~mm}$ de espessura recobrindo ambas as faces. Destacaram-se marcas externas de exposição a fogo brando e desplacamentos arredondados nas faces internas atribuídas à fermentação.

Um terceiro grupo traz potes pequenos e grandes, com adição de argila fina antes do tratamento final de superfície e queima em ambiente redutor. Metade desses potes tem formato cônico, grandes dimensões e marcas de exposição ao fogo, alguns com lascas térmicas na face externa e/ou perfil de oxidação 
indicando o enterramento do vaso durante seu uso, com exposição a altas temperaturas ou exposição prolongada; nas faces internas, depósitos carbônicos apresentam-se em correspondência com as porções oxidadas na face externa, estando a base propriamente dita livre desses resíduos. Destes selecionaram-se os potes 2 e 4 para análise. Estão também nesse grupo potes grandes piriformes, com perfis levemente infletidos, diferentes dos piriformes do outro grupo. Aqui foram selecionados para análise o pote 19 , que exibe revestimento adicional de argila e desgaste de superfície interna associado à fermentação e o pote 20 , sem marcas de fermentação ou de exposição ao fogo, distintamente aos demais piriformes (Rodrigues 2011). Dentre os potes pequenos, analisaram-se o pote 14, globular com $30 \mathrm{~L}$ de capacidade, e os potes 22, hemisférico e o 18 , em meia calota, ambos sem marcas de exposição ao fogo.

Uma ressalva: o autor classificou os potes em globulares e hemisféricos em função do diâmetro da boca em relação ao corpo. No entanto, as pequenas diferenças encontradas nessas relações indicaram a possibilidade dessas morfologias corresponderem a uma única categoria de artefato (Rodrigues com.pess.).

Dentre o material lítico, escolheu-se para análise uma lâmina de machado polida de anfibolito, redirecionado para outro uso após a quebra do gume, provavelmente o processamento de alimentos. $\mathrm{O}$ antigo talão apresenta duas facetas com presença de picoteamento posterior ao polimento original e uma das faces é marcada por uma leve depressão, associada ao uso como "quebra-cocos" (Rodrigues 2011).

\section{Métodos}

A ciência dos alimentos, revisão de etnografias e relatos históricos: o cauim

A ciência dos alimentos

A obra de Osvaldo Lima (1975) traz importantes informações microbiológicas e químicas ao revisitar etnografias referentes à elaboração de bebidas e alimentos fermentados em todas as Américas, descrevendo de forma técnica a obtenção de bebidas e alimentos fermentados alcoólicos ou não, a partir de distintas fontes de amido ou açúcar e de processos os mais diversos.

Na primeira etapa dos processos está sempre a preparação prévia da matéria prima, que no caso do milho poderá se constituir de cozimento, torra, moagem. A partir disto, uma atividade imprescindível para a obtenção de fermentado é a transformação do amido, que é constituído de longas moléculas cuja unidade básica é a glicose, que deverão ser rompidas por enzimas para a produção de açúcares de cadeia curta, fermentescíveis. A operação de quebra da molécula é classificada em 3 tipos: a) realizada através da mastigação, por ação da enzima alfa-amilase contida na saliva; b) permitida pela ação das enzimas alfa e beta amilase liberadas durante o processo de germinação dos grãos (maltagem) e c) por ação de fungos filamentosos, através da enzima amiloglucosidase. Após a ação das enzimas rompendo as macromoléculas do amido, com produção de açúcares de menor tamanho aproveitáveis pelos microrganismos para produção de álcoois e ácidos orgânicos, o insumo então tratado poderá ser encaminhado para os vasos em que se realizará esta operação, a fermentação (Lima 1975).

\section{As etnografias, resenhas e relatos históricos}

O cauim dos Tupinambá da costa foi descrito em diversos relatos do século XVI (Hoehne 1937), sendo o de Hans Staden o mais minucioso. Brochado (1977) descreve a preparação do cauim a partir dos vários subprodutos da mandioca. Este trabalho foi pautado pela ampla revisão feita sobre o cauim dos Tupinambá e Guarani por Noelli e Brochado (1998), que corrobora o sequenciamento de etapas descrito por Staden, sendo repetido de forma similar naqueles grandes grupos, com modificações apenas em função do insumo utilizado (amiláceo e/ou açucarado). Quanto aos artefatos usados, notam os autores a exclusividade de morfologias específicas para cada etapa de elaboração. 
Para povos de idioma Jê, as informações são fragmentárias e originadas a partir do século XIX. Os Jê orientais foram descritos por WiedNeuwied (1942) em 1815, que descreve a elaboração do cauim pelos Camacã do Sul da Bahia:

\begin{abstract}
"Quando fazem uma boa caçada, ou têm outra ocasião qualquer de divertirem, não deixam de celebrar uma festa, acompanhada de dansas e cantos [...]. enquanto os homens trabalham nisso [o corte de uma barriguda (Bombax) para ser usada como vaso de fermentação] as mulheres se ocupam em preparar o 'cain' com mandioca ou milho. Doze ou dezesseis horas antes mastigam os grãos de milho (é a substancia que preferem para tal bebida, mas empregam também batatas), cuspindo num vaso os grãos mastigados e acrescentando depois agua quente; despejam depois a mistura no vaso de casca de árvore, onde continua a fermentação, então, acende-se um fogo por baixo, depois de fixada a base num buraco cavado na terra" (Wied-Neuwied, 1942: 220).
\end{abstract}

Outros relatos, como o de Douville, mencionado em publicação de Métraux (1930 apud Lima 1975), cita para os mesmos Camacãs o uso da etapa de maltagem dos grãos. Os Coroados, habitantes da região entre o rio Paraíba do Sul até o Espírito Santo e Leste de Minas Gerais foram descritos por Spix e Martius (1824) e Freireyss (1906), que relatam formas simplificadas de elaboração da bebida, constituídas de cozimento, mastigação e posterior fermentação usando o mesmo recipiente, de forma cônica, enterrado no chão. Relatos mais recentes mencionam o cauim dos Kaingang, elaborados a partir de pinhões (Aruaucaria sp), adicionados de mel. Botocudos de Santa Catarina e Paraná o produzem a partir do mel (hidromel) (Lima 1975).

Em base ao informado para os Tupinambá, Guarani e Jê, e sob a ótica da Ciência dos Alimentos, a elaboração do cauim alcoólico de milho deve seguir minimamente as seguintes etapas: a) preparação da matéria-prima: cozimento em água e/ou torra e/ou moagem; b) mastigação e insalivação; c) aquecimento (com ação das enzimas na obtenção dos açúcares fermentescíveis); d) fermentação propriamente dita, com a conversão de açúcares menores produzidos pela insalivação em ácidos orgânicos e álcool.

É possível pensar a produção de cauim dos Jê a partir do milho, obedecendo as etapas mínimas mencionadas anteiromente, embora devam ser consideradas, como possibilidades, a torra parcial do milho na etapa a) e a aplicação da germinação dos grãos (maltagem), alternativa à etapa $\mathrm{b}$ ). $\mathrm{O}$ aquecimento do cauim ao final ou durante a sua fermentação também deve ser levado em conta, embora seja apenas mencionado no relato de Wied-Neuwied.

\section{A Arqueobotânica}

Convém inicialmente delimitar o campo de estudo quanto às técnicas empregadas, relativas à Arqueobotânica. Na América do Sul, o termo Arqueobotânica foi sugerido para "práticas vinculadas diretamente ao estudo arqueológico, que partem de investigações com objetivos e perguntas gerais de corte claramente arqueológico, ou seja, dirigidas a uma dinâmica social de per se, mas que requerem a identificação e a interpretação do registro material botânico" (tradução minha, Giovannetti, Capparelli e Pochettino 2008: 30). Estudos arqueobotânicos empregam macro e micro vestígios para discriminar a presença de vegetais em artefatos cerâmicos, líticos, de madeira, coprólitos, cálculos dentários, solos, e outros suportes (Babot 2003; Babot 2007; Coil et al. 2003). Utilizaram-se na presente pesquisa os grânulos de amido como indicadores das plantas que estiveram em contato com os artefatos estudados. Estes apresentam muitas vezes características morfológicas que permitem distinguir a nível de gênero ou espécie em qual vegetal foram sintetizados, o que ocorre baixo controle determinado geneticamente. Para a caracterização dos grânulos de amido, usam-se algumas características básicas indicadas na Fig. 1.

Processos tecnológicos a que foram submetidos, como a moagem, cozimento, torra, desidratação, fermentação etc, provocam alterações tafonômicas nos grânulos de amido, permitindo identificar tais processos (Babot 2007; Henry, Hudson e Piperno 2009; Vinton et al. 2009). As identificações se fazem através de compara- 


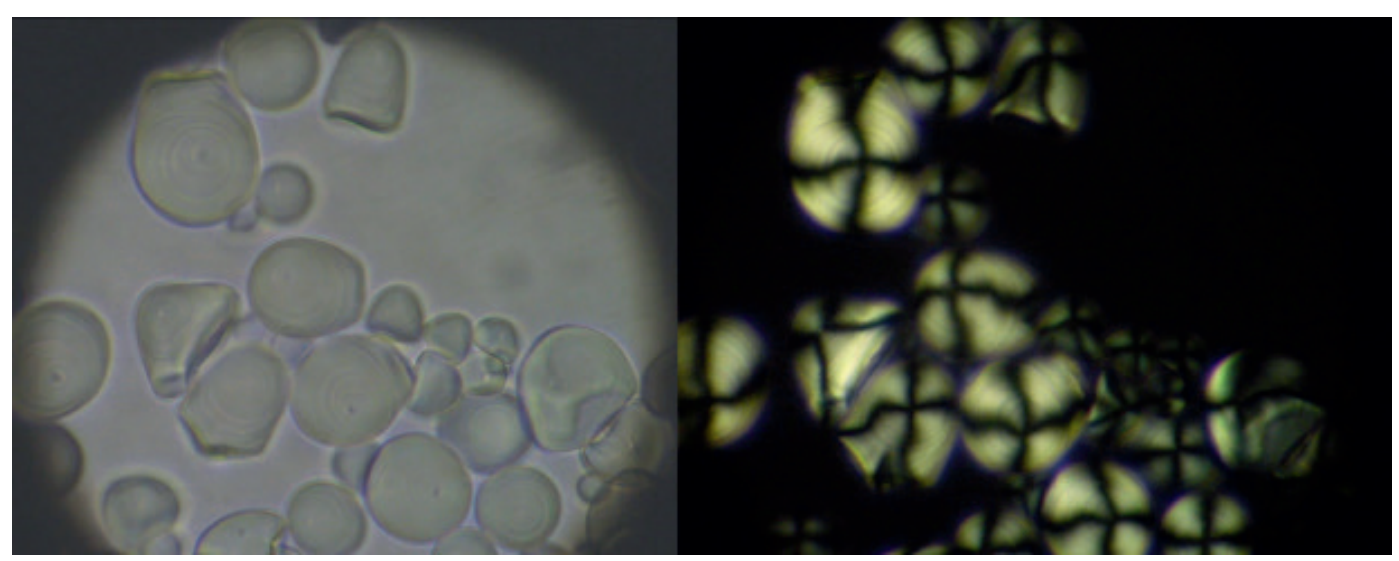

Fig. 1. Características dos grânulos de amido de Ipomoea batatas. À esquerda, sob luz normal, são vistas as lamelas ou anéis de crescimento do grânulo que se desenvolvem em torno ao hilo (ponto onde se inicia a deposição das moléculas constituintes do amido dentro das organelas onde é sintetizado) e bordas arredondadas ou com 1 ou mais facetas de pressão. À direita, sob luz polarizada, observam-se as cruzes de extinção ou de Malta. Foto do autor, aumento 400x, sem barra de escala.

ções com Coleções de Referência para vegetais passíveis de se encontrar no contexto estudado e com Coleções de Amostras-Padrão.

\section{Amostras padrão}

Com a finalidade de ampliar o conhecimento sobre os efeitos tafonômicos exercidos sobre os grânulos de amido pelos procedimentos de transformação dos alimentos empregados na produção do cauim, foram observados grânulos de amido de milho semiduro após: 1) moagem grosseira; 2) torra; 3) mastigação e insalivação; 4) torra e insalivação. Também se observou efeito da mastigação e insalivação sobre o milho verde. $\mathrm{O}$ reconhecimento das alterações morfológicas nos grânulos de amido se faz através de comparação visual com o grânulo intacto em microscópio ótico.

Importante notar que grânulos afetados por determinada etapa do processo permanecem nos artefatos, mesmo em etapas subsequentes (Juan-Tresserras 1998).

Amostragens nos vasos cerâmicos e artefato lítico

As amostragens foram feitas, tanto no material cerâmico como no lítico, através da técnica de gotejamento de água destilada sobre fissuras localizadas em determinadas regiões da peça, seguido de "escavação" com agulha por um tempo determinado, e finalmente succionando o líquido com pipeta descartável de uso exclusivo para cada peça. Os líquidos de amostragens foram acondicionados em tubos eppendorf de $2 \mathrm{~mL}$, sendo acrescidos de glicerina pura de forma a atingir relação 1:1 para água e glicerina. Nos vasos cerâmicos foram escolhidos sempre locais que hipoteticamente estariam: 1) sobre a linha de preenchimento (indicado pela inflexão das paredes ou por marcas nas faces internas); 2) no bojo, em sua parte mediana e 3) na base ou o mais próximo dela. As observações foram feitas em microscópio ótico, com lâminas montadas com uma gota do material coletado e armazenado em glicerina a $50 \%$.

\section{Resultados e interpretação}

Os resultados obtidos nas observações microscópicas em busca de grânulos de amido remanescentes nos artefatos foram interpretados considerando as premissas: 1) o processamento mínimo para obtenção do cauim é constituído de cozimento da matéria-prima, mastigação, aquecimento e fermentação; 2) são opções 
de processo: a moagem, torra e maltagem do milho; 3) há exclusividade na morfologia dos potes para cada etapa; 4) grânulos de amido intactos ou com marcas tafonômicas de uma determinada etapa de processo podem ser encontrados nas etapas seguintes; 5) o uso de utensílios e potes derivados de vegetais não pode ser detectado.

Assim, a atribuição dos utensílios às etapas mínimas e opcionais da produção do cauim foi pensada a partir do cruzamento de 2 tipos de evidências: marcas tafonômicas nos grânulos de amido, indicando a operação tecnológica a que se submeteu o vegetal e/ou marcas de uso dos vasos, apontando para o grau de exposição ao fogo e características do conteúdo. As marcas tafonômicas foram confrontadas com dados de literatura e resultados dos testes anteriormente mencionados.

Inicialmente os grânulos de amido encontrados em vasos globulares mostraram muita semelhança, fortalecendo a premissa de uso de vasos exclusivos, com morfologia definida, para cada etapa do processo. Passou-se então a comparar os grânulos de amido alterados, presentes em cada grupo de vaso com a mesma morfologia, onde notou-se também uma uniformidade nos efeitos tafonômicos para algumas morfologias de vaso. Para cada grupo de vasos foi então buscada a determinação da origem das marcas tafonômicas nos grânulos; quando isto não foi possivel, foram utilizadas as marcas de uso dos vasos para indicar a exposição ao fogo e tipo de alimento neles elaborado.

A seguir, são descritas as possíveis etapas do processo, para as quais são buscados os utensílios mais prováveis (fig. 2), utilizando a metodologia acima citada.

Moagem - no antigo talão da lâmina, usado como parte ativa de mão de pilão, encontraram-se 3 grânulos cf. milho (Zea mays sp) e 2 grânulos cf. batata doce (Ipomoea batatas (L.) Poir.) e 1 grânulo não identificado. Quanto à tafonomia, 1 dos grânulos mostrou sinais de moagem, mas não foi identificada sua origem com segurança. Na face quebra-cocos identificaram-se 3 grânulos cf. milho (Zea mays sp) e 4 grânulos não identificados.
A variedade de grânulos encontrada corrobora a hipótese de uso do artefato para moagem e participação na elaboração de alimentos. Porém, não necessariamente indicam ser este o artefato utilizado para a moagem do milho, já que o único grânulo de amido encontrado com marcas de moagem não foi identificado quanto à taxonomia.

Cozimento - os 3 vasos globulares (14, 17 e 24) exibiram grânulos de amido conforme o milho, com marcas tafonômicas de cozimento, sendo que em dois desses grânulos (nos potes 17 e 24) há marcas identificadas como de moagem. Nas faces externas foram encontradas marcas de fuligem vestigial, porém não foram observadas marcas nas faces internas. Assim, assume-se aqui o uso dos potes globulares para o cozimento do milho moído no início do processo.

Torra - foram consultados dados de literatura e feitos testes com o milho moído, que mostrou o esperado: grumos de grânulos e grânulos com hilo em forma de estrela. Essas marcas não foram observadas em nenhum dos artefatos analisados, e tampouco se encontraram utensílios com morfologia e marcas de uso ao fogo compatíveis com essa operação, sendo sua possibilidade descartada.

Mastigação - em uma fase de pré-testes, foi feita a mastigação de milho torrado, milho verde (fresco) e milho canjicado, que mostraram alterações tafonômicas em concordância com a literatura (Vinton et al. 2009). Porém, não foram localizados microvestígios com essas características nas amostragens feitas nos potes de Vereda III, e assim, não foi possível identificar os potes usados para conter o milho mastigado.

Maltagem - apenas as enzimas alfa amilase e amiloglucosidase possuem especificidade para atacar o grânulo de amido (Haslam 2004: 1719). Portanto, os efeitos tafonômicos do ataque das enzimas da saliva (alfa amilase) e da germinação do grão de milho (enzimas alfa e beta amilases) não devem diferir entre si, já que apenas a alfa amilase deixaria suas marcas. Neste estudo, mesmo que fossem encontrados nos vasos grânulos de amido atacados por enzimas, não se dispunha de técnica nem de informação específica que permitissem distinguir entre maltagem e insalivação. 
Gilberto G. Gardiman

Igor M.M. Rodrigues

Leandro M. Cascon

Andrei Isnardis

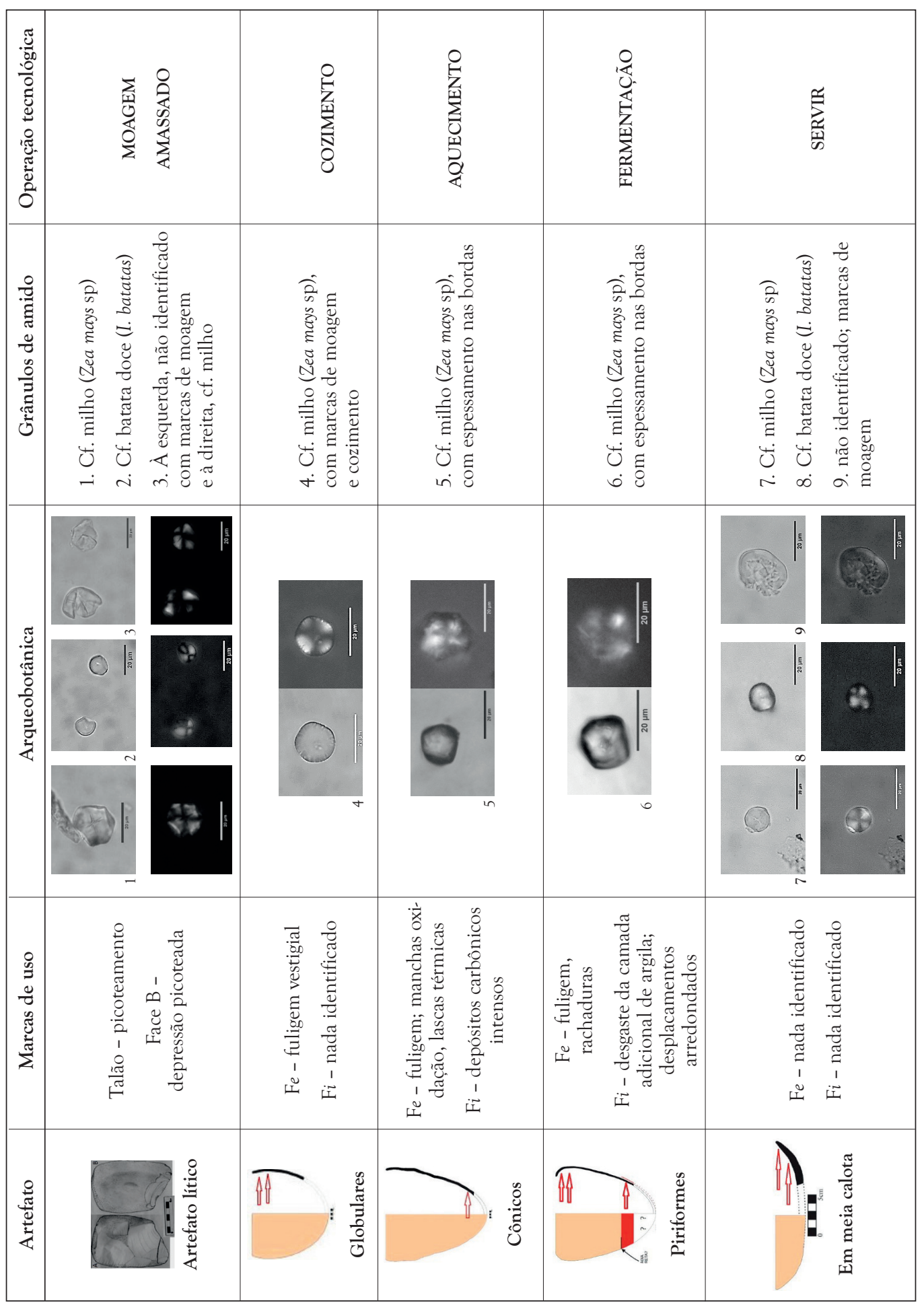

Fig. 2. Artefatos e possível participação no processo de elaboração de alimentos fermentados, marcas de uso; identificação e tafonomia dos grânulos de amido. Obs: Setas em vermelho indicam locais de amostragem; $\mathrm{Fe}$ - face externa; $\mathrm{F} i$ - face interna; Fotos com luz normal sobrepostas às com luz polarizada. 
Aquecimento - para conhecer as marcas tafonômicas impressas nos grânulos até este ponto do processo, ou seja, submetidos a cozimento, mastigação e aquecimento fez-se um teste com milho canjicado branco. Os grânulos resultantes mostraram ao microscópio sob luz polarizada o fechamento dos ângulos retos dos braços de extinção. Essas marcas não foram encontradas nos grânulos extraídos dos vasos de Vereda III. Há, no entanto, uma indicação sobre vasos guaranis de perfil cônico, os yapepó rêbí chûa (Fidryzsewski 2007 apud Neumann 2008) e indicados pela autora como destinados ao aquecimento do caldo antes da fermentação. Os vasos cônicos da coleção de Vereda III exibem muitas coincidências com esses vasos guarani. Externamente trazem marcas intensas de fuligem e, internamente, marcas de resíduo carbônico por grande parte da superfície. A condição para que isto ocorra é a exposição de grandes áreas ao fogo, aliado a um alimento onde há partículas grandes e pequenas (Skibo 1992 apud Neumann 2008), exatamente o que foi observado no teste de aquecimento após o cozimento e mastigação.
Portanto as marcas de uso nos vasos cônicos Jê foram os indicadores da sua utilização na etapa de aquecimento, destinada à formação dos açúcares fermentescíveis a partir do amido.

Fermentação - os vasos piriformes trazem de forma exclusiva marcas de uso que remetem à fermentação. Nas faces internas ocorrem desplacamentos com perfil arredondado, que caracterizam a etapa (Arthur 2002; Neumann 2008; Rodrigues 2011). Na fermentação propriamente dita, a ação dos microrganismos não se dá mais sobre o grânulo de amido, e sim sobre os açúcares produzidos a partir dele, não se esperando por isso encontrar efeito tafonômico sobre os grânulos. Observaram-se apenas grânulos com bordas espessadas, também presentes na etapa anterior (vasos cônicos) e possivelmente provenientes dela.

Servir - a presença diversificada de grânulos de amido, de conformidade com milho, batata doce e leguminosa (possivelmente feijão) no pote 18 , aliado à sua morfologia (prato) e ausência de fuligem são indicações seguras de sua função de servir.

GARDIMAN, G.G.; RODRIGUES, I.M.M.; CASCON, L.M.; ISNARDIS, A. Morphology of Jê vessels in corn cauim production in Vereda III: a proposal. R. Museu Arq. Etn., 27: 111-120, 2016.

\begin{abstract}
An archaeobotanical analysis focused on starch granules extracted from ceramic vessels and a lithic artifact exhumed in Vereda III, MG revealed the widespread presence of corn (Zea mays sp). A previous study of the artifacts detected typical marks of fermentation in some vessels, thus, raised the possibility that more vessels have been used in the production of corn cauim (a fermented alcoholic beverage). The aim of the current research was to understand the production of this drink/food in its multiple possibilities through historical accounts, ethnographies, technological information and tests with fermentation. The taphonomical effects of the various stages of the process on the corn starch granules were investigated in literature and through tests. Here a proposition is made about the morphology of Je vessels used in the preparation of corn cauim, thought from the intersection of two types of evidence: the study of microtrace contained in archaeological artifacts and the trademarks in the vessels.
\end{abstract}

Keywords: Archaeobotany; Fermentation; Fermented corn beverage; Je; Ceramic vessels. 


\section{Referências Bibliográficas}

Arthur, J.W. 2002. Pottery Use-Alteration as an Indicator of Socioeconomic Status: An Ethnoarchaeological Study of the Gamo of Ethiopia. Journal of Archaeological Method and Theory 9 (4): 331-355.

Babot, M.P. 2003. Starch grain damage as an indicator of food processing. In: Hart, D.M., Wallis, L.A. (Orgs.), Phytoliths and starch research in the Australian-Pacific-Asia regions. Australian National University, Terra Australis.

Babot, M.P. 2007. Granos de almidón en contextos arqueológicos: posibilidades y perspectivas a partir de casos del noroeste argentino. In: Marconetto, B., Babot, P., Oliszewski, N. (orgs.). Paleoetnobotánica del cono Sur: Estudios de casos y propuestas metodológicas. Córdoba: Ferreyra Editor. 95-125pp.

Brochado, J.P. 1977. Alimentação na floresta tropical. Porto Alegre: Universidade Federal do Rio Grande do Sul, Instituto de Filosofia e Ciências Humanas, Caderno n 2.

Coil, J.; Korstanje, M.A.; Archera, S.; Hastorf, C. 2003. Laboratory goals and considerations for multiple microfossil extraction in archaeology. Journal of Archaeological Science, 30: 991-1008.

Freireyss, G.W. (1906). Viagem ao interior do Brasil nos anos de 1814-1815. Revista do Instituto Historico e Geographico de São Paulo XI: 158-228. Disponível em: http:// biblio.etnolinguistica.org/freireyss_1906_ viagem; Acessado em: 17/03/2015.

Gardiman, G.G. 2014. Vereda III: uma análise paleoetnobotânica. Monografia de graduação. Universidade Federal de Minas Gerais, Belo Horizonte.

Giovannetti, M.; Capparelli, A.; Pochettino, M.L. 2008. La Arqueobotánica en Sudamérica.
¿Hacia un equilibrio de enfoques? Discusión en torno a las categorías clasificatorias y la práctica arqueobotánica y paleoetnobotánica. In: Archila, S., Giovannetti, M., Lema, V. (Eds.). Arqueobotánica y Teoria Arqueológica: discussiones desde Suramérica. Universidad de los Andes, Facultad de Ciencias Sociales, Departamento de Antropología, CESO, Ediciones Uniandes, Bogotá, 17-34.

Haslam, M. 2004. The decomposition of starch grains in soils: implications for archaeological residue analyses. Journal of Archaeological Sciences, 31: 1715-1734.

Henry, A.G.; Hudson, H.F.; Piperno, D.R. 2009 Changes in starch grain morphologies from cooking. Journal of Archaeological Sciences, 36: 915-922.

Hoehne, F.C. 1937. Botânica e agricultura no Brasil do século XVI. Pesquisas e contribuições. Série $5^{\text {a }}$ Brasiliana vol.71. Companhia Editora Nacional, São Paulo.

Juan-Tresserras, J. 1998. La cerveza pré-histórica: investigaciones arqueobotânicas y experimentales. In: Maya, J.L., Cuesta, F., López, J. (eds.) Genó: um poblado del Bronce Finalen el Bajo Segre (Lleida). Publicacions Universitat de Barcelona, Barcelona, 239-252.

Lima, O.G. 1975. Pulque, balchê e pajauaru. Na etnologia das bebidas e dos alimentos fermentados. Universidade Federal de Pernambuco, Recife.

Neves, W.A.; Kipnis, R.; Araújo, A.; Piló, L.B.; Hubbe, M.O.; Gonçalves, D.; Gloria, P.T.; Hubbe, A.C.; Castro de Oliveira, E.; Auti, J.P.V. (2004). Origens e microevolução do homem na América: uma abordagem paleoantropológica. Relatório. FAPESP, São Paulo.

Neumann, M.A. 2008. Nande-Rekó. Diferentes jeitos de ser Guarani. Dissertação de mestra- 
do. Universidade Federal do Rio Grande do Sul, Porto Alegre.

Noelli, F.S; Brochado, J.P. 1998. O cauim e as beberagens da guarani e tupinambá: equipamentos, técnicas de preparação e consumo. Revista do Museu de Arqueologia e Etnologia, 8: $117-128$.

Rodrigues, 2011. Fora das grandes aldeias: A ocupação do recôndito sítio arqueológico Vereda III. Dissertação de Mestrado. Universidade Federal de Minas Gerais, Belo Horizonte.

Spix, J.B.; Martius, C.F.P. 1824. Travels in Brazil in the years 1817-1820 (Lloyd, H.E., trad.). Longman, Hurst, Rees, Orme, Brown and
Green: London. Disponível em: http:// www.etnolinguistica.org/biblio:spix-martius-1824-travels.

Vinton, S.D.; Perry, L.; Reinhard, K.J.; Santoro, C.M.; Teixeira-Santos, I. 2009. Impact of Empire Expansion on Household Diet: The Inka in Northern Chile's Atacama Desert. PLOS ONE 4(11): e8069. doi: 10.1371/journal.pone.0008069.

Wied-Neuwied, M.P. 1942. Viagem ao Brasil nos anos de 1815 a 1817. Mendonça, Edgard S.; Figueiredo, Flavio P. (trads.). Brasiliana. Série 5a, vol.1. Disponível em: http://www. brasiliana.com.br/obras/viagem-ao-brasilnos-anos-de-1815-a-1817. 